\begin{tabular}{|l|l|}
\hline Postprint Version & 1.0 \\
\hline Journal website & $\underline{\text { http://springerlink.metapress.com/content/102883/ }}$ \\
\hline Pubmed link & $\begin{array}{l}\text { http://www.ncbi.nlm.nih.gov/entrez/query.fcgi?cmd=Retrieve\&db=pubmed\&dop } \\
\text { t=Abstract\&list_uids=15678791\&query_hl=59\&itool=pubmed_docsum }\end{array}$ \\
\hline DOI & $10.1007 /$ s10654-004-2219-1
\end{tabular}

\title{
The consistency of shingles and its significance for health monitoring
}

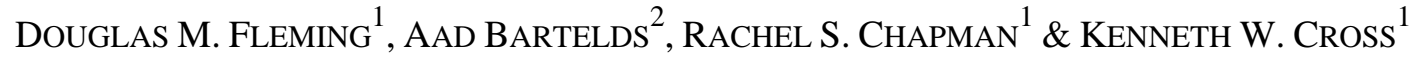 \\ 1 Birmingham Research Unit of the Royal College of General Practitioners, Harborne, Birmingham, \\ UK; \\ 2 NIVEL, Utrecht, The Netherlands
}

\begin{abstract}
.
Accurate estimation of monitored populations is essential for epidemiological study. Many countries do not have systems of patient registration and routine disease surveillance is thereby hindered. We studied the incidence of shingles over time and investigated the hypothesis that the incidence is consistent and could be used as a proxy for estimating the monitored population. Annual incidence rates of shingles reported in the Weekly Returns Service (WRS) since 1970 and in the Dutch Sentinel Network (DSN) over the period 1998-2001 were studied. Gender specific annual rates (1998-2001) were compared after standardising for age. The population in the DSN was estimated by applying the WRS incidence rates to the numbers of DSN incident cases. The incidence of shingles was annually and seasonally consistent. Incidence in males was similar in both networks and in females approximately 18\% greater in the WRS: in age groups 15-64 years, incidence was similar in both networks, but in children 0-14 years and in persons 65 years and over, it was higher in the WRS. The total populations in the DSN estimated from average age/gender specific rates in the WRS were within $12 \%$ of the observed in each of the 4 years surveyed. The incidence of shingles in the two countries was sufficiently close to estimate the surveyed population aged 15-64 years from knowledge of incident cases in the community. Routine monitoring of shingles in sentinel practice networks is commended as a method of assuring recording quality and as a means of estimating the survey population where the registered population is not known.
\end{abstract}

\section{INTRODUCTION}

In a consideration of potential denominators for use in sentinel practice networks where population data are not available, Fleming and Cross [1] drew attention to the consistency of the incidence of shingles and suggested that this condition might be recorded routinely in sentinel practice networks in order to assist in the estimation of the true population denominator. We aimed to estimate the population of the Dutch Sentinel practice network (DSN) from incident cases of shingles recorded in the network applied to the incidence rates reported in the similar sentinel network in England and Wales (the Weekly Returns Service - WRS). The DSN was used because shingles had been included in their routine programme of disease monitoring for several years. 
Published data on the incidence of shingles range between 1.3 and 4.2 cases per 1000 annually [2-9]. The incidence increases with age but estimates of incidence in different countries in different time periods and in populations with different age and ethnic composition are difficult to compare. Ethnicity and geographical origin exert independent effects on the incidence of shingles [10]. Use of the incidence of shingles as a proxy to estimate the denominator, depends on its constancy, at least over a given time period and on a stable threshold for consultation. In most clinical situations the characteristic dermatomal distribution of the rash and the prominent pain are a sufficient basis for diagnosis without further investigation [11].

Shingles is caused by a reactivation of latent varicella- zoster virus (VZV) infection, usually acquired initially as chickenpox in childhood. Re-infection with VZV is recognised [12-15] but is generally considered rare in immuno-competent persons [12-16]. A study of sero-prevalence to VZV in 1623 Belgians age 1-44 years conducted prior to the introduction of VZV vaccination showed 93\% positive sero-prevalence by age 9 years and a similar study involving 21,288 persons in the USA reported $86 \%$ by age 14 yrs $[17,18]$. In both studies antibodies were almost universal by age 40 years indicating that at age 40 the entire population is potentially at risk to reactivation.

\section{MATERIALS AND METHODS}

The WRS of the Royal College of General Practitioners in England and Wales has monitored the incidence of shingles continuously since 1967 [3].

Initially, data were collected using a pro-forma and were grouped by gender (all ages) and by age group (0-4, 5-14, 15-44, 45-64, 65 years and over). By 1994, most practices had been computerised and data were collected separately by gender in each of 8 age groups $(0-1,1-4,5-14,15-24,25-44$, 45-64, 65-74 and 75 years and over). Data collection distinguishes new episodes of illness from ongoing consultations thus allowing examination of incidence (new occurrence rate) as opposed to health care utilisation (consultation rate). Data are extracted from the practice computer once a week providing counts of the population registered and providing counts of new incident cases by diagnosis [19]. The patient registration procedure is maintained centrally for remuneration purposes as part of the National Health Service.

The DSN is a paper based system where general practitioners record on a pro-forma, new incident cases of selected diseases included in the surveillance programme for that year [20]. Shingles was added to the list in 1997 and has been recorded continuously since then. The practices provide counts of their registered population (based on practice maintained registration systems) by gender in 5-year age bands which are updated every 2 years. In each week, practices record the number of days on which they are working and thus recording new incident cases. For this study, the population of the practice in each week was deemed to be the latest updated population if the practice was reporting for five days and prorata for lesser periods. In both countries, general practitioners have a defined list of patients which provides the denominator for calculating rates.

The diagnosis of shingles was made clinically in both networks on the basis of a vesicular eruption with a dermatomal distribution accompanied by pain.

We first examined the incidence of shingles by age group as reported in the WRS since 1970. Weekly incident data were consolidated to provide age specific annual incidence rates. Seasonality was investigated by consolidating the crude incidence data into 4-week periods and averaging the results over the 32 year data set.

Age specific incidence rates in the two networks were compared using consolidated data from the 8 years 1994-2001 WRS and the 4 years 1998-2001 DSN. Gender specific annual incidence rates were calculated standardised to the EU 15 female 1998 standard population in the age groups $0-14,15-24$, 25-44, 45-64, 65-74 and 75 and over in order to compare the incidence in the two networks [21]. The difference between annual incidence rates was calculated along with the $95 \%$ confidence interval.

Finally the DSN population was estimated from the observed number of incident cases in each gender and age group divided by the mean rate observed in the WRS (1994-2001) for that group. The estimates in the 6 age groups were condensed into age groups $0-14,15-64$, and 65 years and over for presentation purposes. These population estimates were compared with the observed population and the error expressed as a percentage of the observed. 


\section{RESULTS}

The mean annual incidence of shingles is presented by age group for the period 1970-2001 in Figure 1. Incidence increased with age and over the 32 year period examined was highly consistent in all age groups excepting 65 years and over where there has been a gradual increase. However, the modal age in this population cohort has increased over the time period.

\section{[ FIGURE 1 ]}

The mean weekly incidence in each of the 4-week periods consolidated over the 32 years was highly consistent averaging 6.6 per 100,000 and ranged between 6.2 and 6.9 in 12 of the 4 week periods but marginally less (5.9) in the last 4 week period of the year. There was no seasonal variation in the DSN network over the period 1998-2001.

The study is based on 5915 male and 8617 female incident cases of shingles in England and Wales and 760 male and 976 female cases in the Netherlands (Table 1). The proportion of male cases was $41 \%$ in the WRS and 44\% in the DSN. In the WRS $16.0 \%$ of cases were less than 25 years of age and in the DSN 14.3\%. Annual incidence rates (WRS, 1994-2001: DSN, 1998-2001) in males ranged between 298 and 365 per 100,000 in the WRS and 282 and 322 in the DSN: and in females between 437 and 489 in the WRS and 353 and 382 in the DSN. In a comparison of the age standardised incidence rates (both male and female rates standardised to the EU15 female population) male rates were similar in the two networks; but female rates were higher in the WRS in 3 of the 4 years, and over the 4 years the average WRS rate was $18 \%$ greater than the DSN equivalent.

\section{[ TABLE 1 ]}

Age specific incidence (per 1000 person years) over the study period (8 years WRS, 4 years DSN) are summarised in Table 2. For both sexes, rates in children and the elderly were higher in the WRS, whereas rates for persons in age groups 15-64 years were similar. In the WRS, incidence in females was higher than males in all age groups except 15- 24 years: in the DSN incidence in females exceeded males in the age group 45-64 years.

\section{[ TABLE 2 ]}

Male and female population estimates for the DSN derived by applying average incidence rates in the WRS data (1994-2001) to incident cases reported in the DSN (1998-2001) were compared with the observed populations in each of the four latter years (Table 3). The accuracy of the male estimate was within $8 \%$ in any one year, though female estimates were less accurate. As a generalisation the accuracy of the male estimate was higher than the female in each of the condensed age groups (Table 4); for each sex the estimate for the 15-64 age group was within 10\% error of the observed.

\section{[ TABLE 3 AND 4 ]}

\section{DISCUSSION}

These data show annual consistency in the incidence of shingles with no seasonal variation. The study included more than 14,000 cases of shingles reported in the WRS in the 8 year period. The incidence rates reported (male and female all ages) in the WRS are similar to those reported previously for the period 1967-1991 [3] where the consistency was contrasted with the incidence of chickenpox which was both seasonally and annually variable with specific epidemic periods clearly identifiable. The consistent female excess incidence over the male in the WRS (evident in all age groups except 15-24) has been reported previously [22] Similar gender differences occurred in the DSN data though these were smaller. 
In spite of the broad similarity of incidence in the two networks there are small differences which may relate to random variation or to differences in health care organisation rather than represent true differences in incidence. Inflation of the observed denominator will result in reduction of the estimate of incidence. In the WRS, the denominator is assessed every week and is the basis for remunerating doctors. In the DSN the denominator is taken from practice age/registers every 2 years. Whilst the procedure is vulnerable to change within the 2 year period, positive and negative changes are likely to balance out. In the Netherlands elderly persons entering nursing homes are not cared for by general practitioners and thus incidence in this group is not included in the estimate reported here. The recording of information following home visits is also an area of potential weakness. In the WRS all contacts are included in the recording exercise and thus procedures are in place to collect information routinely from home visits. The DSN operates through a selective recording framework and it is easy to miss a comparatively infrequent event in the context of the practice recording procedure. In the most frail and elderly, shingles commonly prompts a home visit. Incidence in children was less in the DSN than in the WRS. In a study of the incidence of chickenpox in the two networks, the incidence of chickenpox was also less [23] and it is possible that the threshold for patients to consult is less in the Netherlands, though our data suggest the threshold must be similar in adults. There are many similarities in the delivery of primary healthcare in the UK and in the Netherlands: for example, patient registration with specific practices; access to secondary care limited by referral from primary care; delayed requirements for medical sickness certification. Total consultation rates recorded in respective national morbidity surveys are similar.

Care is needed when comparing all age incidence data from differing studies to ensure that apparent differences are not due to differing population compositions. Donahue et al. reported on 1075 incident cases included in the Harvard Community Health Plan [5] and estimated incidence at 215 per 100,000 person years but this population plan included only $8 \%$ aged 55 years or over, compared with over $20 \%$ in most European countries. When we standardised the incident rates reported by Donahue to the EU15 female population we obtained similar rates (390 for males and 415 for females) to those reported here. Incidence data from Scotland collected as part of the Continuous Morbidity Registration project [24] over the years 1996-1997 and based on a total of 1586 cases of shingles when similarly standardised gave a male rate of 361 and female 475. Reduced incidence has been reported in AfroCaribbean populations though the relative importance of racial/geographical origin is not clear, both may be relevant $[10,25]$ However, not withstanding some considerable sociodemographic changes in the United Kingdom over the last 30 years, the age and gender specific incidence of shingles reported in the WRS has remained remarkably constant.

The findings have implications for disease monitoring in sentinel networks. The incidence of shingles might be used as an indicator of recording quality where the population is believed to be constant. Alternatively, where there is no background knowledge of the population under surveillance, consistency in the number of cases of herpes zoster observed would suggest consistency in the size and age distribution of the underlying population. The similarity of incidence rates between the WRS and DSN across the age range 15-64 years suggest that it may be possible to use age specific incidence rates derived in these two countries as a basis for estimating the underlying population from incident cases monitored elsewhere. This conclusion is reinforced by the incidence estimates published from Germany [6], Italy [7] and France [8]. At least, if the incidence is used to estimate the adult population (15-64 years) other information on the relationship between this population and the numbers of children and of elderly persons could be used. Given present knowledge on racial differences in incidence we would not consider the method outlined here to be robust in circumstances where there has been a recent influx of immigrants.

Epidemiology as a science is dependent upon accurate estimates of the population. However health services in many countries are not delivered to readily definable populations and proxy methods are needed. Even where the health delivery infrastructure would suggest the presence of a reliable population denominator, it is important to consider the accuracy of estimates from other sources. In the UK, the main source of population estimation is the national census. The census validation survey undertaken following the 1991 census in the United Kingdom estimated an undercount of 1.2 million persons representing $2.2 \%$ of the population as a whole. This undercount was not evenly distributed and as a result in making the estimate of a true population in British cities $20 \%$ was added to the 
Fleming, D.M., Bartelds, A., Chapman, R.S., Cross, K.W.

The consistency of shingles and its significance for health monitoring.

European Journal of Epidemiology: 19, 2004, nr. 12, p. 1113-1118

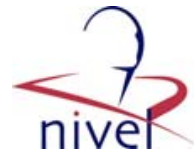

census count for men in their twenties [26]. Set in this context, the accuracy of the estimate derived from incident cases of shingles is high and given the relative ease of monitoring shingles within a practice, we believe this to be an effective tool for estimating populations in sentinel practice networks. We do not advocate the use of this method to estimate the population of an individual practice as the demographic variation in individual practices can be considerable. It is more appropriate to estimating the population of a sentinel network where there is a deliberate effort to secure national representativeness. We would also like to encourage the approach adopted here and stimulate the search for a group of conditions which together have a comparatively large incidence which is sufficiently constant that it would be commended as an even better indication of the monitored population.

\section{ACKNOWLEDGEMENTS}

We are pleased to acknowledge the general practitioners and practice staff in both the sentinel networks, in collecting these data routinely.

\section{TABLES AND FIGURES}

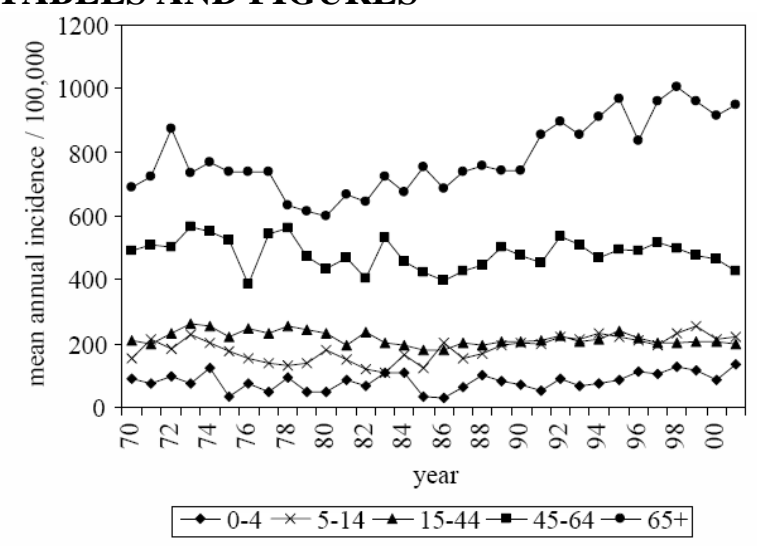

Figure 1. Annual incidence of shingles by age (per 100,000) in patients presenting to general practitioners in the WRS network.

Table 1. Incident cases of shingles by year, annual incidence rate and age standardised incidence rate per 100,000 population by gender and network and differences $(95 \%$ confidence limits) between the network standardised rates

\begin{tabular}{|c|c|c|c|c|c|c|c|}
\hline & \multicolumn{2}{|l|}{ Cases } & \multicolumn{2}{|c|}{ Incidence rate } & \multicolumn{3}{|c|}{ Standardised rates } \\
\hline & WRS & DSN & WRS & DSN & WRS & $\mathrm{DSN}$ & Difference CI \\
\hline \multicolumn{8}{|l|}{ Males } \\
\hline 1994 & 609 & & 343 & & 382 & & \\
\hline 1995 & 638 & & 365 & & 416 & & \\
\hline 1996 & 609 & & 318 & & 355 & & \\
\hline 1997 & 729 & & 330 & & 376 & & \\
\hline 1998 & 732 & 184 & 325 & 283 & 366 & 320 & $46(-14-105)$ \\
\hline 1999 & 905 & 175 & 337 & 282 & 375 & 316 & $59(-0.5-118)$ \\
\hline 2000 & 846 & 211 & 299 & 322 & 339 & 361 & $-23(-79-33)$ \\
\hline 2001 & 847 & 190 & 298 & 308 & 336 & 336 & $0.3(-56-57)$ \\
\hline \multicolumn{8}{|l|}{ Females } \\
\hline 1994 & 876 & & 474 & & 492 & & \\
\hline 1995 & 853 & & 470 & & 486 & & \\
\hline 1996 & 886 & & 447 & & 463 & & \\
\hline 1997 & 1095 & & 481 & & 495 & & \\
\hline 1998 & 1138 & 252 & 489 & 375 & 497 & 402 & $95(34-157)$ \\
\hline 1999 & 1211 & 248 & 437 & 382 & 443 & 406 & $37(-21-96)$ \\
\hline 2000 & 1280 & 249 & 440 & 362 & 448 & 379 & $70(13-126)$ \\
\hline 2001 & 1278 & 227 & 438 & 353 & 444 & 362 & $82(25-140)$ \\
\hline
\end{tabular}


Fleming, D.M., Bartelds, A., Chapman, R.S., Cross, K.W.

The consistency of shingles and its significance for health monitoring.

European Journal of Epidemiology: 19, 2004, nr. 12, p. 1113-1118

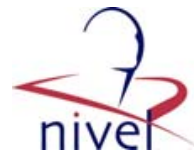

Table 2. Incidence of shingles per 100,000 person years and $95 \%$ confidence limits, by age group and network

\begin{tabular}{|c|c|c|c|c|c|c|}
\hline \multirow[t]{2}{*}{ Age } & \multicolumn{3}{|l|}{ WRS } & \multicolumn{3}{|l|}{ DSN } \\
\hline & Cases & Incidence & CI & Cases & Incidence & CI \\
\hline \multicolumn{7}{|l|}{ Males } \\
\hline $0-14$ & 585 & 162 & $149-176$ & 57 & 122 & $92-158$ \\
\hline $15-24$ & 476 & 212 & $193-232$ & 67 & 217 & $168-276$ \\
\hline $25-44$ & 1119 & 199 & $187-211$ & 204 & 236 & $205-271$ \\
\hline $45-64$ & 1776 & 399 & $381-417$ & 236 & 384 & $337-436$ \\
\hline $65-74$ & 1090 & 775 & $730-822$ & 115 & 650 & $537-780$ \\
\hline $75+$ & 869 & 958 & $895-1024$ & 81 & 728 & $578-905$ \\
\hline \multicolumn{7}{|l|}{ Females } \\
\hline 0-14 & 795 & 231 & $218-234$ & 74 & 166 & $130-208$ \\
\hline $15-24$ & 462 & 211 & $192-231$ & 52 & 161 & $120-211$ \\
\hline $25-44$ & 1361 & 245 & $232-258$ & 196 & 227 & $196-261$ \\
\hline $45-64$ & 2598 & 591 & $569-614$ & 341 & 561 & $503-624$ \\
\hline $65-74$ & 1578 & 984 & $936-1034$ & 158 & 753 & $640-880$ \\
\hline $75+$ & 1823 & 1104 & $1054-1156$ & 155 & 773 & $656-905$ \\
\hline
\end{tabular}

Table 3. DSN population estimates obtained by applying the WRS incident rates to the DSN incident cases by year

\begin{tabular}{|c|c|c|c|c|c|c|c|c|c|}
\hline & \multicolumn{3}{|l|}{ Males } & \multicolumn{3}{|c|}{ Females } & \multicolumn{3}{|c|}{ Males + Females } \\
\hline & Est & Obs & $\%$ error & Est & Obs & $\%$ error & Est & Obs & $\%$ error \\
\hline 1998 & 60140 & 65011 & -7.5 & 56867 & 67231 & -15.4 & 116329 & 132242 & -12.0 \\
\hline 1999 & 57961 & 62049 & -6.6 & 55848 & 64851 & -13.9 & 114231 & 126900 & -10.0 \\
\hline 2000 & 69711 & 65557 & 6.3 & 57547 & 68802 & -16.4 & 125820 & 134359 & -6.4 \\
\hline 2001 & 63901 & 61777 & 3.4 & 54307 & 64286 & -15.5 & 117147 & 126063 & -7.1 \\
\hline
\end{tabular}

Table 4. DSN population estimates obtained by applying the WRS incident rates to the DSN incident cases by age group

\begin{tabular}{|c|c|c|c|c|c|c|c|c|c|}
\hline & \multicolumn{3}{|l|}{ Males } & \multicolumn{3}{|c|}{ Females } & \multicolumn{3}{|c|}{ Males + Females } \\
\hline & Est & Obs & $\%$ error & Est & Obs & $\%$ error & Est & Obs & $\%$ error \\
\hline $0-14$ & 35292 & 46741 & -24.5 & 32042 & 44659 & -28.3 & 67060 & 91400 & -26.6 \\
\hline $15-64$ & 193129 & 178834 & 8.0 & 162425 & 179490 & -9.5 & 353234 & 358323 & -1.4 \\
\hline $65+$ & 23292 & 28820 & -19.2 & 30102 & 41022 & -26.6 & 53233 & 69842 & -23.8 \\
\hline
\end{tabular}

\section{REFERENCES}

1. Fleming DM, Cross KW. Comparison and harmonisation of denominator data for primary health care research in countries of the European Community. In: Schlaud M (ed), Biomedical health research. Amsterdam: IOS Press, 1999, pp. 119-120.

2. Hope-Simpson RE. The nature of HZ: A long term study and a new hypothesis. Proc R Soc Med 1965, 58: 9-12.

3. Fleming DM, Norbury CA, Crombie DL. Annual and seasonal variation in the incidence of common diseases. Br J Gen Pract 1991; 53.

4. Wilson JB. Thirty one years of herpes zoster in a rural practice. Br Med J 1986; 293: 1349-1351.

5. Donahue JG, Choo PW, Manson JE, Platt R. The incidence of herpes zoster. Arch Intern Med 1995; 155: 1603-1609.

6. Meister W, Neiss A, Gross G, et al. Demography, symptomatology, and course of disease in ambulatory zoster patients. A physician-based survey in Germany. Intervirology 1998; 41: 272-277.

7. di Luzio Paparatti U, Arpinelli F, Visona G. Herpes zoster and its complications in Italy: An observational survey. J Infect 1999; 38: 116-120.

8. Chidiac C, Bruxelle J, Daures JP, et al. Characteristics of patients with herpes zoster on presentation to practitioners in France. Clin Infect Dis 2001; 33: 62-69.

9. Brisson M, Edmunds WJ, Law B, et al. Epidemiology of varicella zoster virus infection in Canada and the United Kingdom. Epidemiol Infect 2001; 127: 305-314.

10. Nagasako EM, Johnson RW, Griffin DR, Elpern DJ, Dworkin RH. Geographic and racial aspects of herpes zoster. J Med Virol 2003; 70 (Suppl 1): S20-S23.

11. Liesegang TJ. Varicella viral disease. Mayo Clin Proc 1999; 74: 983-998. 
12. Gershon AA, Steinberg SP, Gelb L. Clinical reinfection with varicella-zoster virus J Infect Dis 1984; 149: 137-142.

13. Junker AK, Angus E, Thomas EE. Recurrent varicellazoster virus infections in apparently immunocompetent children. Pediatr Infect Dis J 1991; 10: 569-575.

14. Terada K, Kawano S, Shimada Y, Yagi Y, Kataoka N. Recurrent chickenpox after natural reinfection. Pediatr Infect Dis J 1996; 15: 179-181.

15. Martin KA, Junker AK, Thomas EE, Van Allen MI, Friedman JM. Occurrence of chickenpox during pregnancy in women seropositive for varicella-zoster virus. J Infect Dis 1994; 170: 991-995.

16. Gershon AA, Takashashi W. In: Plotkin SA, Orenstein WA (eds), Vaccines. Philadelphia: WB Saunders Co, 1999; 477.

17. Thiry N, Beutels P, Shkedy Z, Vranckx R, Vandermeulen C, Wielen Damme PV. The seroepidemiology of primary varicella-zoster virus infection in Flanders (Belgium). Eur J Pediatr. 2002; 161: 588-593. Epub 2002 Sep 24.

18. Kilgore PE, Kruszon-Moran D, Seward JF, et al. Varicella in Americans from NHANES III: implications for control through routine immunization. J Med Virol 2003; 70 (Suppl 1): S111-S118.

19. Fleming DM. Weekly returns service of the Royal College of General Practitioners. Commun Dis Public Health 1999 2: 96-100.

20. Bartelds AIM, Fracheboud J, van der Zee J. The Dutch sentinel practice network; relevance for public health policy. Netherlands Institute of Primary Health Care Utrecht, The Netherlands.

21. Eurostat. Demographic Statistics 1999. Office for Official Publications of The European Community, Luxembourg.

22. Fleming DM, Cross KW, Cobb WA, Chapman RS. Gender difference in the incidence of shingles Epidemiol Infect 2003; 132; 1-5.

23. Fleming DM, Schellevis FG, Falcao I, Alonso TV, Padilla LP. The incidence of chickenpox in the community. Eur J Epidemiol 2001; 17: 1023-1027.

24. Scottish CMR project 'Practice Team Information' http://www.show.scot.nhs.uk/isd/cmr/ 25. Schmader K, George LK, Burchett BM, Pieper CF, Hamilton JS. Racial differences in the occurrences of herpes zoster. J Infect Dis 1996; 174: 329-341.

26. Simpson S. 1991 population estimates for areas smaller than districts. Population Trends Winter 1997 Office for National Statistics, London.

Address for correspondence: Douglas M. Flemong, Birmingham Research Unit of the Royal College of General Practitioners, Lordswood House, 54, Lordswood Rd, Harborne, Birmingham B17 9DB, UK Phone: +44-121-426-1125; Fax: +44-121-428-2084 E-mail: dfleming@rcgpbhamresunit.nhs.uk 